\title{
A Ryanodine Receptor-like Molecule Expressed in the Osteoclast Plasma Membrane Functions in Extracellular $\mathrm{Ca}^{2+}$ Sensing
}

\author{
Mone Zaidi, *‡ Vijai S. Shankar, * Richard Tunwell, ${ }^{5}$ Olugbenga A. Adebanjo, ${ }^{\star \ddagger}$ John Mackrill, ${ }^{5}$ Michael Pazianas, ${ }^{*}$ \\ David O'Connell, ${ }^{\mathbf{5}}$ Bruce J. Simon, * Barry R. Rifkin," Ashok R. Venkitaraman,' Christopher L.-H. Huang, ** \\ and F. Anthony Lais \\ *St. George's Hospital Medical School, University of London, London SW17 ORE, United Kingdom; ${ }^{\ddagger}$ Department of Medicine, \\ University of Arkansas for Medical Sciences and GRECC, Little Rock 72205; ${ }^{8}$ National Institute for Medical Research, Mill Hill, London \\ NW7 1AA, United Kingdom; "Basic Sciences Division, New York University Dental School, New York 10010; 'MRC Laboratory of \\ Molecular Biology, Cambridge CB2 2QH, United Kingdom; and ** The Physiological Laboratory, University of Cambridge, Cambridge \\ CB2 3EG, United Kingdom
}

\begin{abstract}
Ryanodine receptors (RyRs) reside in microsomal membranes where they gate $\mathrm{Ca}^{2+}$ release in response to changes in the cytosolic $\mathrm{Ca}^{2+}$ concentration. In the osteoclast, a divalent cation sensor, the $\mathrm{Ca}^{2+}$ receptor ( $\mathrm{CaR}$ ), located within the cell's plasma membrane, monitors changes in the extracellular $\mathrm{Ca}^{2+}$ concentration. Here we show that a RyR-like molecule is a functional component of this receptor. We have demonstrated that $\left[{ }^{3} \mathrm{H}\right]$ ryanodine specifically binds to freshly isolated rat osteoclasts. The binding was displaced by ryanodine itself, the $\mathrm{CaR}$ agonist $\mathrm{Ni}^{2+}$ and the $\mathrm{RyR}$ antagonist ruthenium red. The latter also inhibited cytosolic $\mathrm{Ca}^{2+}$ elevations induced by $\mathrm{Ni}^{2+}$. In contrast, the responses to $\mathrm{Ni}^{2+}$ were strongly potentiated by an antiserum $\mathrm{Ab}^{129}$ raised to an epitope located within the channel-forming domain of the type II RyR. The antiserum also stained the surface of intact, unfixed, trypan blue-negative osteoclasts. Serial confocal sections and immunogold scanning electron microscopy confirmed a plasma membrane localization of this staining. Antiserum $\mathbf{A b}^{34}$ directed to a putatively intracellular RyR epitope expectedly did not stain live osteoclasts nor did it potentiate CaR activation. It did, however, stain fixed, permeabilized cells in a distinctive cytoplasmic pattern. We conclude that an RyR-like molecule resides within the osteoclast plasma membrane and plays an important role in extracellular $\mathrm{Ca}^{2+}$ sensing. ( $J$. Clin. Invest. 1995. 96:1582-1590.) Key words: bone resorption $\cdot \mathrm{Ca}^{2+}$-sensing receptor • osteoclast • osteoporosis • ryanodine receptor
\end{abstract}

\section{Introduction}

Membrane depolarization, neurotransmission, and hormone action all trigger the release of $\mathrm{Ca}^{2+}$ from intracellular stores (13 ). This release results from the opening of either inositol tris

Address correspondence to Christopher L.-H. Huang, The Physiological Laboratory, Downing Street, Cambridge CB2 3EG, United Kingdom. Phone: 44-1223-333822; FAX: 44-1223-333840.

Received for publication 19 December 1994 and accepted in revised form 25 May 1995

J. Clin. Invest.

(C) The American Society for Clinical Investigation, Inc.

0021-9738/95/09/1582/09 \$2.00

Volume 96, September 1995, 1582-1590 phosphate receptors or ryanodine receptors (RyRs). ${ }^{1}$ Both are $\mathrm{Ca}^{2+}$ release channels located within microsomal membranes.

The RyRs form a small family of closely related proteins. Type I RyR, found in skeletal muscle, mediates sarcoplasmic reticular $\mathrm{Ca}^{2+}$ release that occurs in response to tubular membrane depolarization. The latter is sensed by a cell surface dihydropyridine receptor $(4,5)$. Types II and III occur in a wide variety of cells and gate $\mathrm{Ca}^{2+}$ release in response to changes in the cytosolic $\mathrm{Ca}^{2+}$ concentration. This process is termed $\mathrm{Ca}^{2+}$. induced $\mathrm{Ca}^{2+}$ release (6). RyRs may therefore have a more general role in biology in monitoring changes in the concentration of $\mathrm{Ca}^{2+}$.

It has recently been discovered that certain cells can monitor changes in the extracellular $\mathrm{Ca}^{2+}$ concentration using a plasma membrane divalent cation-sensing receptor, the $\mathrm{Ca}^{2+}$ receptor (CaR) $(7,8)$. Such cells include osteoclasts $(9,10)$, parathyroid chief cells $(7,11)$, thyroid $C$ cells $(12,13)$, juxtaglomerular cells (14), enterocytes (15), and keratinocytes (16). Cationinduced activation of a given $\mathrm{CaR}$ results in the generation of intracellular signals that in turn modify cell function. Thus, these cells can all be regulated by exposure to changing concentrations of extracellular $\mathrm{Ca}^{2+}$.

Osteoclasts, when exposed to millimolar $\mathrm{Ca}^{2+}$ concentrations, respond with rapid increases in the cytosolic $\mathrm{Ca}^{2+}$ concentration $(9,10)$. This triggers a dramatic cell retraction followed by a profound inhibition of bone resorption $(10,17,18)$. These morphological and functional changes may form part of an important feedback control mechanism. Excessive bone resorption will therefore generate increases in the ambient $\mathrm{Ca}^{2+}$ concentration that should limit further osteoclast activity.

We have previously established the use of the divalent cation $\mathrm{Ni}^{2+}$ as an alternative agonist for the osteoclast $\mathrm{CaR}$. We demonstrated that even low micromolar concentrations of $\mathrm{Ni}^{2+}$ can elicit changes in cytosolic $\mathrm{Ca}^{2+}$ and cell function similar to those produced by millimolar $\mathrm{Ca}^{2+}$ concentrations $(19,20)$. Responses to $\mathrm{Ni}^{2+}$ showed features expected for drug-receptor interactions such as concentration-dependent activation and usedependent inactivation (19). Moreover, $\mathrm{Ni}^{2+}$ and $\mathrm{Ca}^{2+}$ appeared to trigger the same receptor $(20)$. The cytosolic $\mathrm{Ca}^{2+}$ response to millimolar extracellular $\mathrm{Ca}^{2+}$ was thus inhibited by $\mathrm{Ni}^{2+}$ and vice versa. Additionally, extracellular $\mathrm{Ca}^{2+}$ was found to modulate the cytosolic $\mathrm{Ca}^{2+}$ responses to varying $\mathrm{Ni}^{2+}$ concentrations (19).

We have also shown that the osteoclast $\mathrm{CaR}$ resides within

1. Abbreviations used in this paper: $\left[\mathrm{Ca}^{2+}\right], \mathrm{Ca}^{2+}$ concentration; $\mathrm{CaR}$, $\mathrm{Ca}^{2+}$ receptor; RyR, ryanodine receptor. 
the plasma membrane. Firstly, CaR function is modified by changing the cell's membrane potential. This would suggest that the molecule is resident within the plasma membrane and is thus exposed to its electric field $(21,22)$. Secondly, the CaR agonist $\mathrm{Ni}^{2+}$ is itself membrane impermeant $(23,24)$. Yet, it causes the release of $\mathrm{Ca}^{2+}$ from intracellular stores $(19,25)$. Thirdly, the proteolytic enzyme pronase that is known to cleave surface proteins in intact cells abolishes $\mathrm{Ni}^{2+}$-induced $\mathrm{CaR}$ activation (26). These findings together confirm that $\mathrm{Ni}^{2+}$ acts at a specific surface membrane site that is presented extracellularly.

We have recently suggested that a ryanodine- and caffeinesensitive pathway is involved in $\mathrm{CaR}$ activation in the osteoclast $(27,28)$. Both RyR modulators, ryanodine and caffeine, were found to attenuate cytosolic $\mathrm{Ca}^{2+}$ responses to $\mathrm{Ni}^{2+}$. We therefore went on to explore the effects of other agents known to interact with the known RyRs, including the polycationic dye ruthenium red, and a panel of isoform- and region-specific antiRyR antibodies. Using a combination of independent biophysical, autoradiographic, and immunocytochemical techniques, we show that a RyR-like molecule is a functional component of the osteoclast $\mathrm{CaR}$. This study demonstrates for the first time a plasma membrane location for an RyR-like molecule.

\section{Methods}

Preparation of antisera to RyR Isoforms. The amino acid sequences of the three mammalian RyR isoforms, types I, II, and III, were analyzed for identity using the Wisconsin software package (Plotsimilarity, GCG, University of Wisconsin, Madison, WI). This comparison revealed a region of marked sequence divergence present between amino acids 4100 and 4800 (Fig. 1 a). From this region of striking sequence dissimilarity, isoform-specific peptide sequences for types I, II, and III RyR were identified. These were analyzed against each one of the amino acid sequences present in the Leeds and Swissprot Protein Databases (Blastp, GCG, University of Wisconsin). We identified a unique 22 amino acid sequence that is located between the predicted transmembrane segments 6 and 7 of the type II RyR (between amino acids 4643 and 4815; marked by the asterisk in Fig. 1 a) (29). A peptide corresponding to this epitope was synthesized using an Applied Biosystems Peptide Synthesizer (model 430A Applied Biosystems, Inc., Foster City, Co.;). It was subsequently coupled through an additional $\mathrm{COOH}$ terminal cysteine to keyhole limpet hemocyanin using the bifunctional reagent, sulfo-SMCC (Pierce, United Kingdom).

For antibody production, rabbits were injected subcutaneously with $250 \mu \mathrm{g}$ of the peptide keyhole limpet hemogenic conjugate in Freund's complete adjuvant followed by booster injections, at 28-d intervals, in Freund's incomplete adjuvant. The rabbits were bled $14 \mathrm{~d}$ after each injection and the titre of the resulting antiserum was determined by an ELISA. Its specificity was also determined by immunoblotting with rabbit cardiac microsomal membranes. Antiserum $\mathrm{Ab}^{129}$ was found to possess a high titre and was specific for the type II RyR found in cardiac microsomes (also see below). Similarly, antisera $\mathrm{Ab}^{180}$ and $\mathrm{Ab}^{34}$ were produced by immunization of rabbits with peptides corresponding to an epitope on the type III RyR and a conserved calmodulin-binding region of the RyR family, respectively.

SDS-polyacrylamide gel electrophoresis and immunoblot analysis. SDS-polyacrylamide gel electrophoresis was performed using $8 \%$ separating and 3\% stacking polyacrylamide gels using a minigel system (Bio Rad Laboratories, Cambridge, United Kingdom). Microsomes prepared from various tissues $\left(50 \mu \mathrm{g}\right.$ ) were heated for $5 \mathrm{~min}$ at $95^{\circ} \mathrm{C}$ in loading buffer ( $2 \% \mathrm{wt} / \mathrm{vol}$ SDS, $2 \% \mathrm{vol} / \mathrm{vol} \beta$-mercaptoethanol, $10 \% \mathrm{vol} / \mathrm{vol}$ glycerol and $50 \mu \mathrm{g} /$ liter bromophenol blue in $0.1 \mathrm{M}$ Tris-HCI buffer, $\mathrm{pH}=6.8$ ) (29). Electrophoresis was performed at a constant current ( 20 $\mathrm{mA} / \mathrm{gel})$. The separated proteins were either stained with Coomassie Brilliant Blue (R-250; Sigma Chemical Co., Poole, United Kingdom) or electrophoretically transferred onto polyvinylidene difluoride membranes (Immobilon; Millipore Corp., Milford, MA) at $15^{\circ} \mathrm{C}$ for $1 \mathrm{~h}$ at $400 \mathrm{~mA}$, then at $1,500 \mathrm{~mA}$ for $15 \mathrm{~h}$. The transfer membranes were blocked with nonmilk proteins ( $4 \% \mathrm{wt} / \mathrm{vol})$, and then incubated overnight at $4^{\circ} \mathrm{C}$ with antiserum $\mathrm{Ab}^{129}$ ( 1 in 1,000$)$. After washing and a further incubation with a peroxidase-coupled anti-rabbit antibody, the blot was developed with 3,3'-diaminobenzidine and hydrogen peroxide.

Osteoclast culture. Osteoclasts were obtained by curetting long bones obtained from neonatal Wistar rats killed by cervical dislocation into $1 \mathrm{ml}$ Hepes-buffered medium 199 (ICN Flow UK; Middlesex, United Kingdom) supplemented with FCS ( $5 \%$ vol/vol) (GIBCO, Middlesex, United Kingdom). The resulting suspension was agitated gently and dispersed onto 22-mm, 0-grade, glass coverslips (Chance Propper, Smethwick, Warley, United Kingdom) placed in the wells of a multiwell dish. Within a 15 -min incubation period $\left(37^{\circ} \mathrm{C}\right)$, osteoclasts readily sedimented upon, and attached to the glass substrate. Contaminating cells were then removed by rinsing the coverslips with medium 199 . Osteoclasts were readily identified by their large size, multinuclearity, complex morphology, and densely ruffling edges. Furthermore, the cells quiesced and then retracted in response to the application of a low picomolar concentration of calcitonin (30).

Cytosolic $\left[\mathrm{Ca}^{2+}\right]$ measurements. For measurements of the cytosolic $\mathrm{Ca}^{2+}$ concentration $\left(\left[\mathrm{Ca}^{2+}\right]\right)$, coverslips containing freshly isolated osteoclasts were incubated for $30 \mathrm{~min}$ at $37^{\circ} \mathrm{C}$ with $10 \mu \mathrm{M}$-fura $2 / \mathrm{AM}$ (Calbiochem, Nottingham, United Kingdom) in serum-free medium (31). They were then washed in medium 199 and transferred to a Perspex bath positioned on the stage of a microspectrofluorimeter. The latter was previously constructed from an inverted microscope (Diaphot, Nikon, Telford, United Kingdom). The cells were then exposed to prewarmed $\left(37^{\circ} \mathrm{C}\right)$ test solutions of $\mathrm{NiCl}_{2}(5 \mathrm{mM})$ made up in medium 199. In different experiments, osteoclasts were first conditioned by incubating, for between 3 and 4 minutes, with either ruthenium red (at concentrations of $5,50,500 \mathrm{nM}, 50$ or $100 \mu \mathrm{M}$, diluted in medium 199 ) or with either of the two anti-RyR antisera, $A b^{129}$ or $A b^{34}$ (see below) (1:50, diluted in Medium 199). It should be emphasized that cells were preincubated with the antisera at room temperature $\left(20^{\circ} \mathrm{C}\right)$ so that antibody internalization was minimized. In a separate set of experiments, $100 \mu \mathrm{M}$ of peptide (see below) was also included in the conditioning treatment before the addition of $\mathrm{Ab}^{129}$. The remaining antisera, i.e., anti-type I RyR and $A b^{180}$, were not tested in this system as they failed to stain osteoclasts in preliminary immunocytochemical studies (see below).

The cells were exposed alternatively to excitation wavelengths of either 340 or $380 \mathrm{~mm}$ approximately every second. The emitted fluorescence was deflected through a $400-\mathrm{nm}$ dichroic mirror and the transmitted light was filtered at $510 \mathrm{~nm}$. The resulting fluorescent beam was then directed to a photomultiplier tube (PM28B; Thorn EMI, London, United Kingdom) which converted the signal into 25-ns, 5-V, transistortransistor-logic (TTL) pulses. These were counted by a dual photon counter (Newcastle Photometric Systems, Newcastle-upon-Tyne, United Kingdom). Photon counts were recorded every second in a microcomputer (IBM Corp., Armonk, NY) to give the ratio of emitted intensities due to excitation at 340 and $380 \mathrm{~nm}\left(\mathrm{~F}_{340} / \mathrm{F}_{380}\right)$.

The cytosolic $\left[\mathrm{Ca}^{2+}\right]$ measuring system was calibrated using an established protocol for intracellular calibration $(19,31)$. Briefly, fura 2-loaded osteoclasts were bathed in a $\mathrm{Ca}^{2+}$-free, EGTA-containing solution consisting of $130 \mathrm{mM} \mathrm{NaCl}, 5 \mathrm{mM} \mathrm{KCI}, 5 \mathrm{mM}$ glucose, $0.8 \mathrm{mM}$ $\mathrm{MgCl}_{2}, 10 \mathrm{mM}$ Hepes and $0.1 \mathrm{mM}$ EGTA. $5 \mu \mathrm{M}$ ionomycin was first applied to obtain the minimum ratio due to lowest cytosolic $\left[\mathrm{Ca}^{2+}\right]$ $\left(R_{\min }\right)$ and the maximal fluorescent intensity at $380 \mathrm{~nm}\left(F_{\max }\right) .1 \mathrm{mM}$ $\mathrm{CaCl}_{2}$ was then applied together with $5 \mu \mathrm{M}$ ionomycin to obtain values of the maximum ratio due to elevated cytosolic $\left[\mathrm{Ca}^{2+}\right]\left(\mathrm{R}_{\max }\right)$ and the minimum fluorescent intensity at $380 \mathrm{~nm}\left(\mathrm{~F}_{\min }\right)$. The dissociation constant $\left(\mathrm{K}_{\mathrm{d}}\right)$ for $\mathrm{Ca}^{2+}$ and fura 2 at a temperature of $20^{\circ} \mathrm{C}$, an ionic strength of $0.1 \mathrm{M}$, and a pH of 6.85 is $224 \mathrm{nM}$. The values were substituted into the equation: cytosolic $\left[\mathrm{Ca}^{2+}\right]=\mathrm{K}_{\mathrm{d}} \times\left[\left(\mathrm{R}-\mathrm{R}_{\min }\right) /\left(\mathrm{R}_{\max }-\mathrm{R}\right)\right]$ $\times\left[\left(\mathrm{F}_{\max } / \mathrm{F}_{\min }\right)\right]$.

$\left[{ }^{3} \mathrm{H}\right]$ ryanodine binding. Freshly isolated osteoclasts were incubated 
with $\left[{ }^{3} \mathrm{H}\right.$ ]ryanodine (DuPont-NEN, Boston, MA) for $1 \mathrm{~h}$ with or without $100 \mu \mathrm{M}$ ryanodine (Calbiochem), $5 \mathrm{mM} \mathrm{NiCl}_{2}$ (Sigma Chemical Co.) or $100 \mu \mathrm{M}$ ruthenium red (Calbiochem). Each well of a plastic multiwell plate (Sterilin, London, United Kingdom) was loaded with $100 \mu \mathrm{l}$ of a solution of bovine serum albumin in medium $199(0.1 \%$, wt/vol) (BSA/ medium 199). The osteoclast-containing coverslips were then washed in BSA/medium 199 and placed in the respective wells. Aliquots of $100 \mu \mathrm{l}\left[{ }^{3} \mathrm{H}\right]$ ryanodine, diluted in BSA/medium 199 to give counts of around $8 \times 10^{6} \mathrm{~min}^{-1} \mathrm{ml}^{-1}$, were then transferred to each well. This provided an effective molar concentration of around $15 \mathrm{nM}$ of $\left[{ }^{3} \mathrm{H}\right]$ ryanodine. After their incubation at room temperature for $1 \mathrm{~h}$, the coverslips were removed, washed in an aqueous solution of formalin (10\% $\mathrm{vol} / \mathrm{vol}$ ) for $10 \mathrm{~s}$ and rinsed in water. They were then allowed to dry and mounted onto glass microscope slides.

K5 emulsion gel ( $3 \mathrm{ml}$; Eastman Kodak Co. London, United Kingdom) was melted in the dark and mixed with $3 \mathrm{ml}$ glycerol (Sigma Chemical Co.). The ends of each slide were dipped into this mixture ensuring that the coverslips were completely covered. They were then placed on a storage rack, transferred to dark boxes, wrapped in black bags, and stored overnight. The slides were stored in light-proof storage boxes at $4^{\circ} \mathrm{C}$ for $7 \mathrm{~d}$ after which they were allowed to warm to room temperature and placed in Coplin jars. Finally, they were developed, fixed, counterstained (with hematoxylin), dehydrated (in a series of graded aqueous alcohol solutions between 20 and 100\%, vol/vol) and mounted. Multinucleated osteoclasts were viewed through a light microscope (Optiphot; Nikon).

Immunocytochemistry and confocal microscopy. The immunocytochemical studies used a panel of polyclonal antisera raised in the rabbit against either the type I RyR or synthetic peptides corresponding to specific epitopes on the type II and type III RyRs (see above). Ab ${ }^{129}$ and $\mathrm{Ab}^{180}$ were specific to corresponding short regions located within the channel-forming, $\mathrm{COOH}$-terminal, domains of the type II and type III RyRs, respectively. In contrast, $\mathrm{Ab}^{34}$ was directed against a consensus calmodulin-binding sequence in the central, presumed cytoplasmic, domain of the RyR family.

Coverslips containing osteoclasts were incubated with normal goat serum (diluted with $10 \mathrm{mM}$ PBS, 1:10, pH-7.4) in multiwell dishes (Sterilin) for $15 \mathrm{~min}$. The excess serum was then removed and replaced with HBSS (GIBCO) or nonimmune rabbit serum (in control wells). Antisera $A b^{129}$ and $A b^{34}$ were diluted in medium 199 (1:50, vol/vol) and added to the respective test wells. In separate experiments, osteoclasts were first permeabilized with Triton X-100 (0.1\%, vol/vol Sigma Chemical Co.) and then stained with $\mathrm{Ab}^{34}$. After a 1-h incubation, the coverslips were rinsed gently with HBSS, drained, and reincubated for a further hour with goat anti-rabbit FITC (Sigma Chemical Co.) (1:20, diluted in HBSS). Finally, the coverslips were washed gently with HBSS and drained.

For visualization of osteoclasts, coverslips were mounted onto the base of a Perspex bath on the stage of a microspectrofluorimeter (see above). The filter-containing wheel was adjusted to position a FITC filter $(510 \mathrm{~nm})$ in the optical path. Osteoclasts were then viewed under phase contrast optics before visualization under epifluorescence. The number of fluorescent osteoclasts were determined. After each experiment, trypan blue ( $1 \mathrm{mM}$, molecular mass $=961 \mathrm{D}$, Sigma Chemical Co.) was applied to exclude significant damage to the osteoclast membrane that could allow antibody access into the cytosol.

For confocal microscopy, the coverslips were mounted onto glass slides. Osteoclasts were visualized using laser scanning confocal microscope systems fitted with Ne-Ar lasers (MRC600; Bio Rad Laboratories and Carl Zeiss Oberkochen Ltd., Dusseldorf, Germany). For each experiment, we first counted the number of osteoclasts that stained with $\mathrm{Ab}^{129}$ (in the absence or presence of its peptide) or with $\mathrm{Ab}^{34}$ (intact or permeabilized cells). Osteoclasts that exhibited fluorescence were then sectioned optically in the laser-scanning mode. To confirm a localization of the positive staining to the osteoclast membrane, $1-\mu \mathrm{m}$ thick optical sections were obtained in the z-axis of the cell's coronal plane in selected experiments.

Immunogold labeling and scanning electron microscopy. Osteo- clasts, isolated onto glass coverslips as described above, were first incubated with normal goat serum (diluted with $10 \mathrm{mM}$ PBS, 1:10, pH7.4) in multiwell dishes (Sterilin) for $15 \mathrm{~min}$. The excess serum was then removed and the coverslips were washed with HBSS. Either antiserum $\mathrm{Ab}^{129}$ or nonimmune rabbit serum (diluted in medium 199;1:50, $\mathrm{vol} / \mathrm{vol}$ ) were added to the wells and the coverslips incubated for $1 \mathrm{~h}$ on ice. They were then washed three times in medium 199, incubated for a further $6 \mathrm{~h}$ with goat anti-rabbit antiserum (coupled to $30 \mathrm{~nm}$ wide gold particles) (Agar, United Kingdom), rinsed gently with medium 199, and placed in a refrigerator for $18 \mathrm{~h}$. Subsequently, the cells were fixed with glutaraldehyde ( $10 \%$, vol/vol) for $15 \mathrm{~min}$, washed with HBSS, and dehydrated in graded aqueous alcohol (50-90\%, vol/vol). The coverslips were then sputter coated with gold using a coating device and examined under a scanning electron microscope (model 940; Carl Zeiss, Oberkochen). A high magnification allowed the visualization of gold particles on the cell surface. Up to 15 fields per cell were examined each for the control and antibody-treated cells.

\section{Results}

Antibody specificity. The plot in Fig. 1 a shows an analysis of similarity between the three mammalian RyR isoforms after an optimal alignment of the corresponding sequences using the Wisconsin Software Package (Pileup, GCG). All three sequences are very similar and display an overall identity of $70 \%$ (Fig. $1 a$ ). However, there are several regions of marked sequence divergence, the largest being at the carboxyl terminal one-fifth of the molecule from amino acids 4100 to 4800 of the alignment. We used this strategy to identify peptide sequences unique to each RyR isoform. The peptide sequences so identified were used to scan the Swissprot and Leeds Databases to confirm their lack of similarity to any other known protein sequence before being used to raise isoform- and epitope-specific antisera (see above).

Fig. $1 b$ shows an immunoblot of skeletal muscle, cardiac muscle, and brain microsomal membranes probed with antiserum $\mathrm{Ab},{ }^{129}$ specifically raised against the type II RyR. A high molecular weight band corresponding to the type II RyR protein was found to be expressed in cardiac muscle (lane 2), and at lower levels (lane 3), in brain microsomes. These results are in agreement with those from previous studies $(32,33)$. In contrast, no immunoreactive bands were observed with skeletal muscle microsomal membranes (lane 1) where the type I, but not the type II RyR, is highly expressed (Coomassie-stained gels not shown). These studies therefore indicated that antiserum $A b^{129}$ specifically recognized the type II RyR protein. It is also noteworthy that the antiserum also did not detect members of the related family of inositol tris-phosphate receptors that are normally found within brain microsomal membranes.

Thus, the results of our searches of the Swissprot and Leeds Databases indicating a lack of similarity of our sequence with any other known peptide, taken together with our results from immunoblot analysis confirming the specific binding of $A b^{129}$ to the type II RyR, constitute strong evidence for the isoformand epitope-specificity of this antiserum.

Biophysical studies. Fig. 2 illustrates the effect of a range of concentrations of ruthenium red on the magnitude of cytosolic $\mathrm{Ca}^{2+}$ transients elicited upon the application of $5 \mathrm{mM}$ $\mathrm{Ni}^{2+}$. In the absence of ruthenium red, a peak elevation of cytosolic $\left[\mathrm{Ca}^{2+}\right]$ was observed within $25 \mathrm{~s}$ of $\mathrm{Ni}^{2+}$ application. This was followed by a monotonic decline of cytosolic $\left[\mathrm{Ca}^{2+}\right]$ over the next 20-60 s to near-basal values. These observations are consistent with our previous results (19). Pretreatment of 


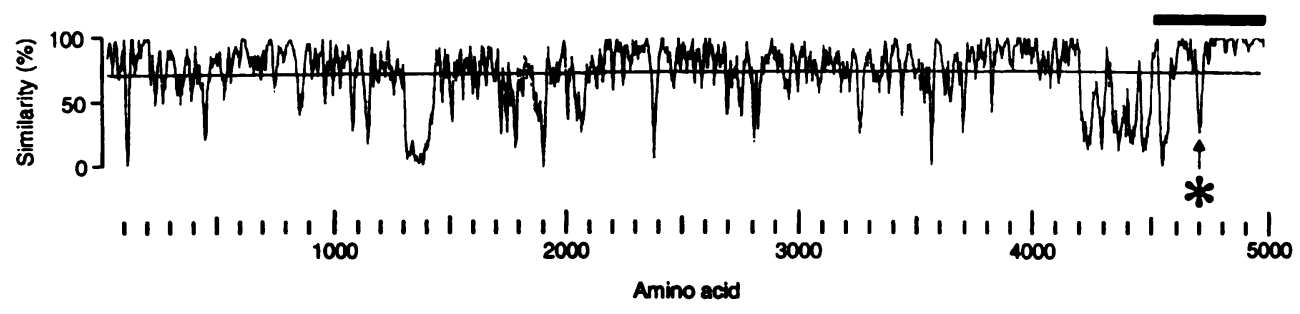

b

123

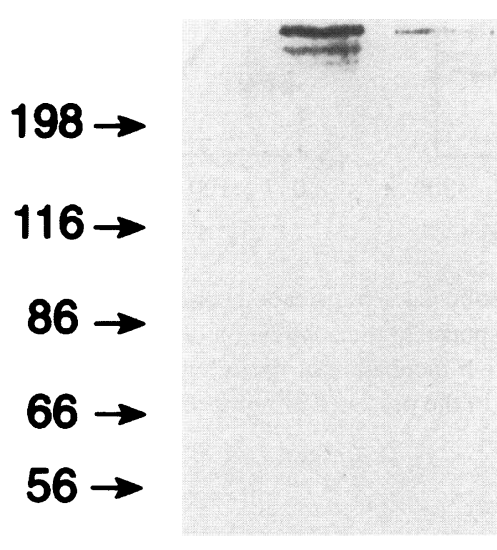

Figure 1. (A) Similarity plot obtained from an optimal alignment of the three known mammalian RyR isoforms (see Methods). Overall identity of $70 \%$ is shown by the thin line throughout the trace. The carboxyl terminal region encompassing the predicted transmembrane segments are shown by a solid bar, and the location of the type II-specific antibody epitope by the asterisk. $(B)$ Skeletal (lane 1), cardiac (lane 2), and brain (lane 3 ) microsomes ( $50 \mu \mathrm{g} /$ lane) were electrophoresed through a $8 \%$ SDS polyacrylamide gel and electrophoretically transferred onto an Immobilon membrane (Millipore Corp.) at $15^{\circ} \mathrm{C}$ for $1 \mathrm{~h}$ at 400 $\mathrm{mA}$, then at $1,500 \mathrm{~mA}$ for $15 \mathrm{~h}$. The membrane was blocked for $1 \mathrm{~h}$ with $4 \%$ nonfat proteins, then probed with the antitype II $\mathrm{RyR}$ antiserum, $\mathrm{Ab}^{129}$. The membrane was developed by peroxidase-coupled anti-rabbit IgG and 3,3'-diaminobenzidine/hydrogen peroxide. The arrows indicate the positions of $M_{\mathrm{T}}$ standards $\left(\times 10^{3}\right)$. The second band seen in lane 2 is a well-characterized degradation artefact.

osteoclasts for 3 mins with a range of ruthenium red concentrations ( $5 \mathrm{nM}-100 \mu \mathrm{M})$ markedly reduced the peak change in the cytosolic $\mathrm{Ca}^{2+}$ response to applied $\mathrm{Ni}^{2+}$ in a concentrationdependent manner (Fig. 2).

The inset of Fig. 2 summarizes the results from between 4 and 11 cells studied at each ruthenium red concentration. Cytosolic $\Delta\left[\mathrm{Ca}^{2+}\right]$, calculated as the difference between the basal and peak cytosolic $\left[\mathrm{Ca}^{2+}\right]$, is plotted against the logarithmic ruthenium red concentration. A least squares curve fit assuming a single binding site yielded a $K_{\mathrm{i}}$ of $\sim 46.3 \mathrm{nM}$, close to the values of ruthenium red binding to RyRs of excitable cells.

In muscle, ruthenium red blocks $\mathrm{Ca}^{2+}$ release only when applied intracellularly $(4,34)$, in keeping with its large, highly charged, membrane-impermeant nature. In contrast, in the osteoclast, the $\mathrm{Ni}^{2+}$-sensitive $\mathrm{CaR}$ appeared to be accessible to extracellularly applied ruthenium red, suggesting its location at or near the osteoclast surface. This led us to investigate the effects of the region-specific anti-RyR antibodies, $A b^{129}$ and $\mathrm{Ab}^{34}$, on $\mathrm{CaR}$ activation by $\mathrm{Ni}^{2+}$. Fig. 3 shows that preincubation of intact rat osteoclasts with $\mathrm{Ab}^{129}$ resulted in a dramatic 10-fold potentiation of the cytosolic $\left[\mathrm{Ca}^{2+}\right]$ change elicited upon $\mathrm{Ni}^{2+}$ application. Thus, the cytosolic $\Delta\left[\mathrm{Ca}^{2+}\right]$ was increased from $380 \pm 84$ in control cells (mean \pm SEM $n=12$ cells; Fig. $3 a)$ to $3,862 \pm 992 \mathrm{nM}(n=8$ cells; Fig. $3 b)$ in $\mathrm{Ab}^{129}$-pretreated cells.

Two control experiments attest to the specificity of this potentiation. First, the inclusion, during the preincubation period, of the peptide against which antiserum $\mathrm{Ab}^{129}$ was raised, abolished the observed potentiation (Fig. $3 c$ ). Secondly, prein- cubation with antiserum $\mathrm{Ab}^{34}$ did not affect the $\mathrm{Ni}^{2+}$-induced cytosolic $\mathrm{Ca}^{2+}$ elevation (Fig. $3 d$ ).

None of the treatments resulted in membrane permeabilization as assessed by the following criteria. Firstly, the cells retained their ability to exclude the vital dye, trypan blue. For this, $1 \mathrm{mM}$ trypan blue was applied to the cells after each run and the osteoclasts were then viewed under phase contrast optics. There was no evidence of dye uptake in osteoclasts that had previously responded to $\mathrm{Ni}^{2+}$. Secondly, we monitored for any time-related drifts in cytosolic $\left[\mathrm{Ca}^{2+}\right]$ that would result from ion leakage through the cell membrane, and which should precede trypan blue entry. Finally, we monitored fluorescence counts $\left(\mathrm{F}_{340}\right)$ over time to exclude leakage of the fluorochrome, fura 2 (molecular mass $=1 \mathrm{kD}$ ). No significant ion or dye leakage was observed over the relevant experimental periods. Taken together, the evidence makes remote the possibility that the antibody entered the cytosol through a permeable cell membrane.

Autoradiographic studies. To provide further independent evidence for an RyR-like molecule, we performed autoradiographic studies using $\left[{ }^{3} \mathrm{H}\right]$ ryanodine $(15 \mathrm{nM})$. Fig. $4 a$ shows a high level of $\left[{ }^{3} \mathrm{H}\right]$ ryanodine binding to isolated osteoclasts. This binding was completely abolished by a 100 -fold molar excess unlabeled ryanodine, confirming specificity (Fig. $4 b$ ). It should be noted however, that inferences cannot be drawn on the localization of this binding as $\left[{ }^{3} \mathrm{H}\right]$ ryanodine freely crosses the cell membrane. Nevertheless, the findings confirm the presence of an RyR-like molecule in the osteoclast.

We next tested whether ruthenium red, which we had found 


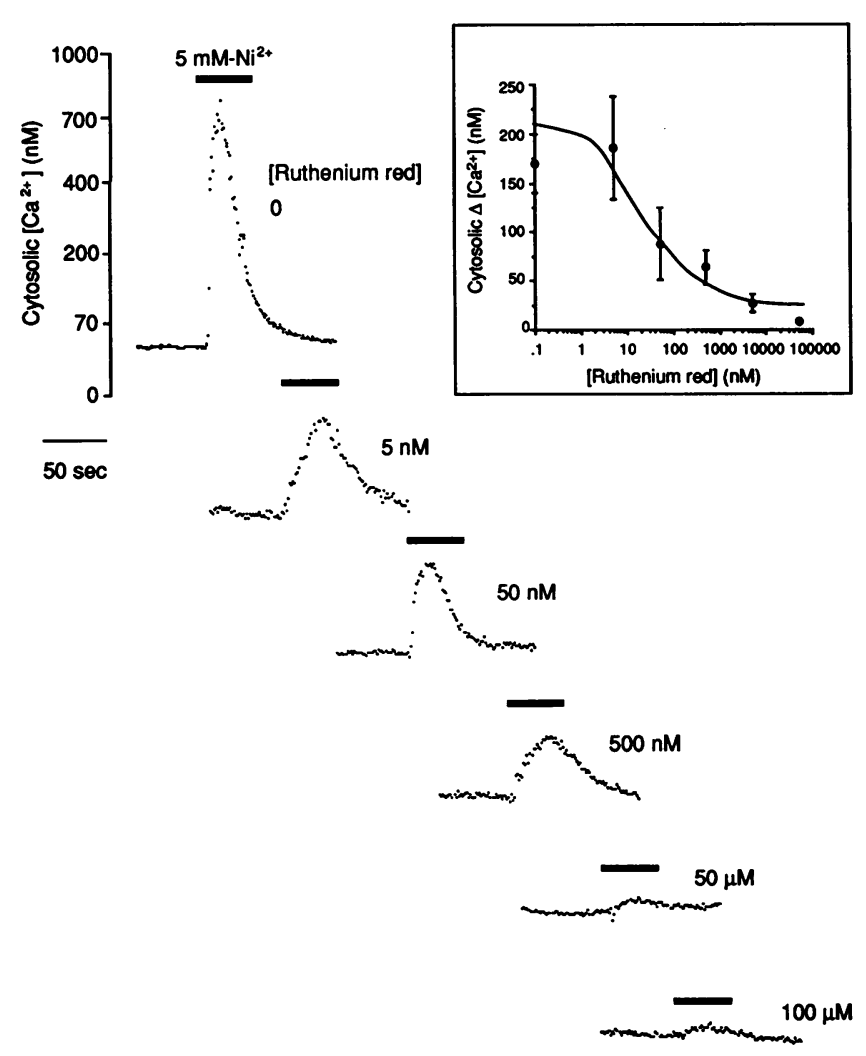

Figure 2. Representative cytosolic $\mathrm{Ca}^{2+}$ transients recorded from single fura 2-loaded osteoclasts in response to the application of $\mathrm{NiCl}_{2}(5 \mathrm{mM}$; $\mathrm{Ni}^{2+}$; closed bar). The cells were preincubated for $3 \mathrm{~min}$ with either vehicle or a range of concentrations of ruthenium red $(5,50,500 \mathrm{nM}$, 50 , or $100 \mu \mathrm{M})(n=4-11$ cells for each ruthenium red concentration $)$. (Inset) Logarithmic concentration-response plot for the inhibitory effect of ruthenium red on the peak change in cytosolic $\mathrm{Ca}^{2+}$ concentration $\left(\Delta\right.$ cytosolic $\left.\left[\mathrm{Ca}^{2+}\right], \mathrm{nM}\right)$ elicited in response to the application of $\mathrm{NiCl}_{2}(5 \mathrm{mM})$. Each data point represents the mean \pm SEM $(n=4-11$ cells for each ruthenium red concentration). The curve shows the least squares fit assuming a single binding site for ruthenium red. This gave a $K_{1}$ of $46.3 \mathrm{nM}$.

interacts with the osteoclast $\mathrm{CaR}$ (Fig. 2), directly competes with ryanodine for its binding sites. Fig. $4 \mathrm{c}$ shows that there was a significant reduction of $\left[{ }^{3} \mathrm{H}\right]$ ryanodine binding in the presence of ruthenium red $(100 \mu \mathrm{M})$. In particular, the peripheral membrane and the adjoining cytoplasm which are in focus in Fig. $4 c$ show a clear loss of silver grains. These results further support the possibility of there being interacting binding sites for ruthenium red and ryanodine. That ruthenium red is polycationic and is thus cell impermeant, suggests that its binding will be localized to the cell's surface membrane. As would therefore be expected, ruthenium red did not displace bound $\left[{ }^{3} \mathrm{H}\right]$ ryanodine completely, and that some binding, which was presumably intracellular, still remained obvious.

We went on further to explore whether the surface action of $\mathrm{Ni}^{2+}$ also influenced the binding of ryanodine to its receptor. Fig. $4 d$ shows that the inclusion of $5 \mathrm{mM} \mathrm{Ni}^{2+}$ during the incubation of osteoclasts with $\left[{ }^{3} \mathrm{H}\right]$ ryanodine did, albeit only partially, displace the radioactive tracer. Taken together with results from our studies that used antiserum $\mathrm{Ab},{ }^{129}$ these findings strongly suggest that an RyR-like molecule is a functional component of the osteoclast $\mathrm{CaR}$.
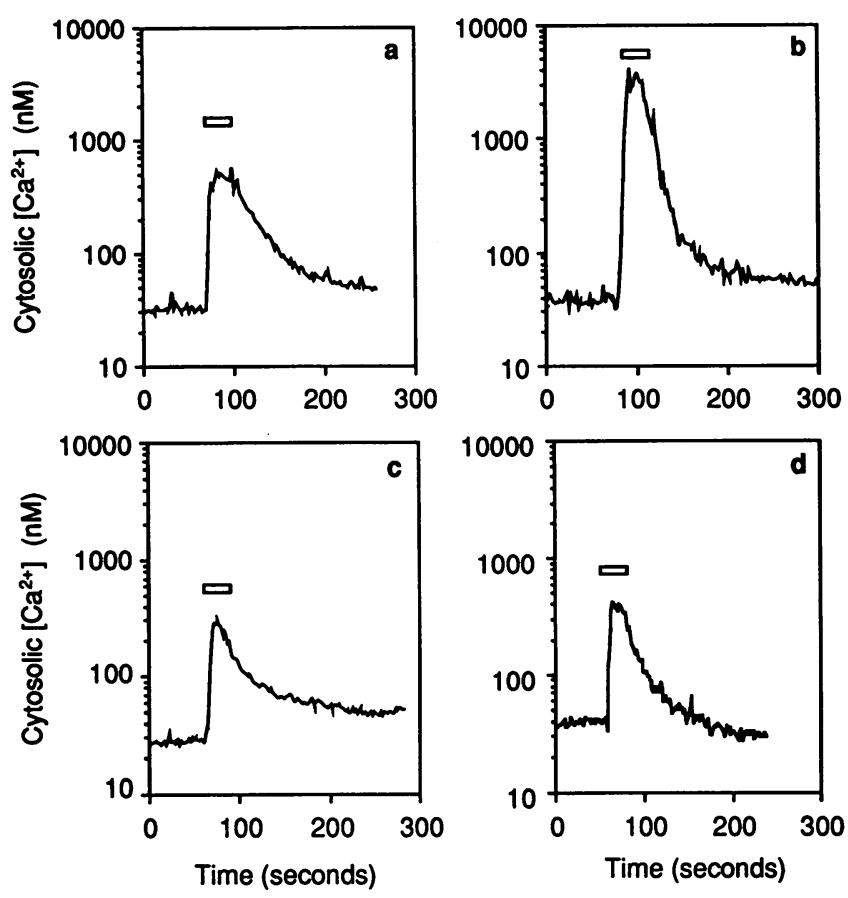

Figure 3. Representative cytosolic $\mathrm{Ca}^{2+}$ transients recorded from single fura 2-loaded osteoclasts in response to the application of $\mathrm{NiCl}_{2}(5 \mathrm{mM}$; $\mathrm{Ni}^{2+}$; open bar) following a 1-h incubation at room temperature with vehicle $(a), \mathrm{Ab}^{129}(b), \mathrm{Ab}^{129}$ in the presence of competing peptide $(c)$ or $\mathrm{Ab}^{34}(d)$.

Immunocytochemical and confocal microscopic studies. We next attempted to examine, in a manner independent of the above, whether the RyR-like molecule was resident in the plasma membrane. We considered this imperative in view of the absence of any previous report for the localization of RyRs to any cell surface membrane.

We thus examined whether the antisera, anti-type I RyR, $\mathrm{Ab}^{129}, \mathrm{Ab},{ }^{180}$ and $\mathrm{Ab},{ }^{34}$ bound to intact live osteoclasts. Fig. 5 $a$ demonstrates staining of the osteoclast membrane with antiserum $\mathrm{Ab}^{129}$. Fig. $5 b$ shows, in addition, a marked peripheral glow that is reminiscent of a plasma membrane staining pattern. All osteoclasts examined (49 cells) showed a positive staining with this antiserum. Osteoclasts did not stain with the anti-type I RyR antiserum or with $\mathrm{Ab}^{180}$

Control experiments were performed by $(a)$ not including antiserum $\mathrm{Ab},{ }^{129}(b)$ using nonimmune rabbit serum in place of $\mathrm{Ab}^{129}$ and $(c)$ including the competing peptide $(100 \mu \mathrm{M})$ before and during incubation with $\mathrm{Ab}^{129}$. No staining was observed without the antiserum or with nonimmune rabbit serum. Inclusion of the peptide sharply reduced the intensity of staining. Either no staining was observed or only a faint glow detected (Fig. $5 \mathrm{c}$ ). Moreover, intact live osteoclasts ( 60 out of 60 cells examined) did not stain with the antiserum $\mathrm{Ab}^{34}$. This, together with our negative findings with the anti-type I RyR antiserum and $A b^{180}$, provided further negative controls.

Additionally, all osteoclasts retained their ability to exclude trypan blue (see above). This confirmed that their cell membranes were intact, and thus remained impermeable to the antibody. Furthermore, other trypan blue-negative cells in the preparation, including osteoblasts, fibroblasts and lymphocytes, were found not to stain with $\mathrm{Ab}^{129}$ suggesting a specific localization of the immunofluorescence to the osteoclast. 


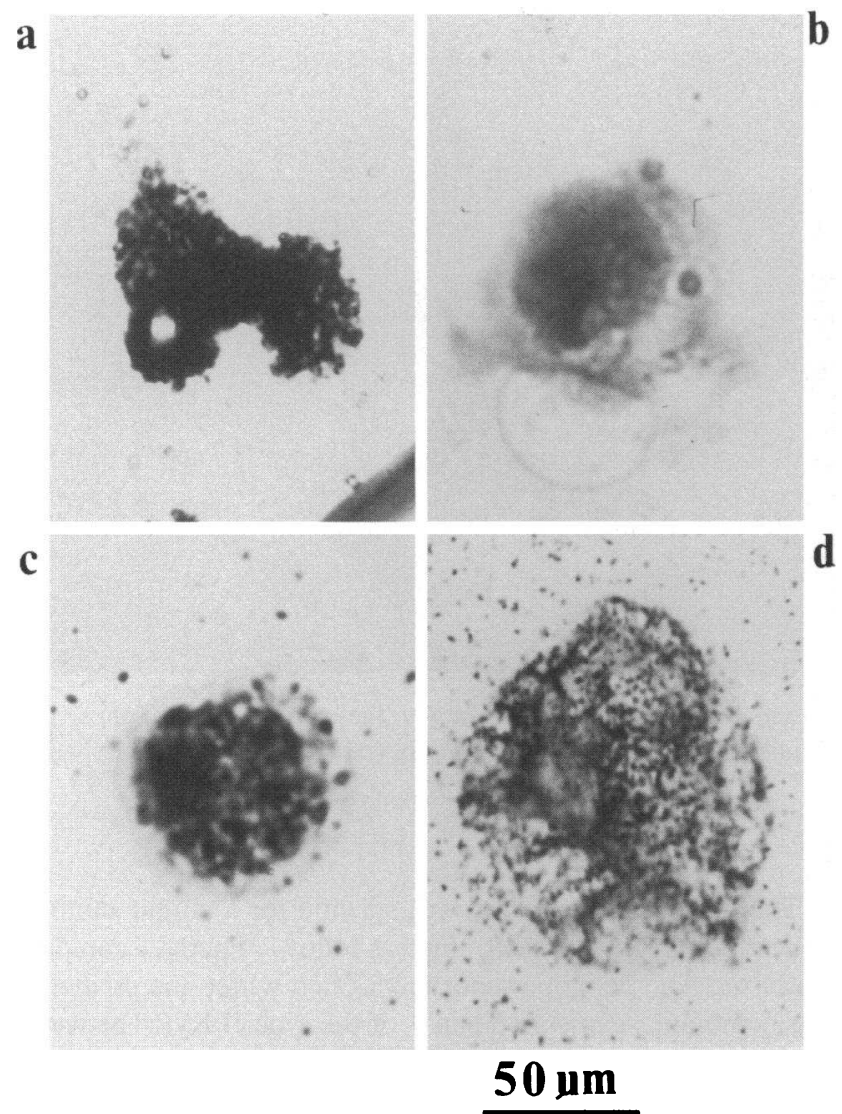

Figure 4. Autoradiographs of isolated osteoclasts that were incubated with $15 \mathrm{nM}\left[{ }^{3} \mathrm{H}\right]$ ryanodine in the presence of vehicle $(a, n=18), 100$ $\mu \mathrm{M}$-unlabeled ryanodine $(b, n=16), 100 \mu \mathrm{M}$ ruthenium red $(c, n=$ $4)$, or $5 \mathrm{mM} \mathrm{NiCl}_{2}(d, n=3)$.

We further examined the localization of the RyR-like molecule by confocal microscopy. Confocal images obtained by sectioning each cell through a single optical plane demonstrated a peripheral $\mathrm{Ab}^{129}$ staining typical of a plasma membrane pattern (Fig. $6 a$ ). Every one of the 1,000 osteoclasts examined in different experiments showed staining. The peripheral staining pattern was consistently observed through the series of confocal sections taken at $1-\mu \mathrm{m}$ intervals in the $\mathrm{z}$-axis of the cell's coronal plane (Fig. 7). These findings thus reinforced the localization of $\mathrm{Ab}^{129}$ binding to the osteoclast plasma membrane. Again, preincubation of the cells with $\mathrm{Ab}^{129}$ together with its competing peptide resulted in either no staining or a markedly attenuated staining in all of the 300 osteoclasts studied (Fig. $6 \mathrm{~b}$ ).

It has already been pointed out that the antiserum $\mathrm{Ab}^{34}$ did not stain intact live osteoclasts corroborating a lack of its effect on $\mathrm{CaR}$ activation. Nevertheless, when osteoclasts were permeabilized with Triton X-100 and then stained with $A b,{ }^{34}$ a characteristic intracellular staining pattern with a clear nuclear outlining was apparent in all of the 60 cells examined (Fig. 8).

Immunogold localization studies. To further confirm that antiserum $\mathrm{Ab}^{129}$ bound to the osteoclast surface membrane, we chose to perform scanning electron microscopy using a goat anti-rabbit second antibody coupled to $30-\mathrm{nm}$ wide gold particles. Fig. 9 shows scanning electron micrographs (negative images) of the surface of osteoclasts at high magnifications (all scale bars $=30 \mathrm{~nm}$ ). Panel $a$ shows the surface of a typical
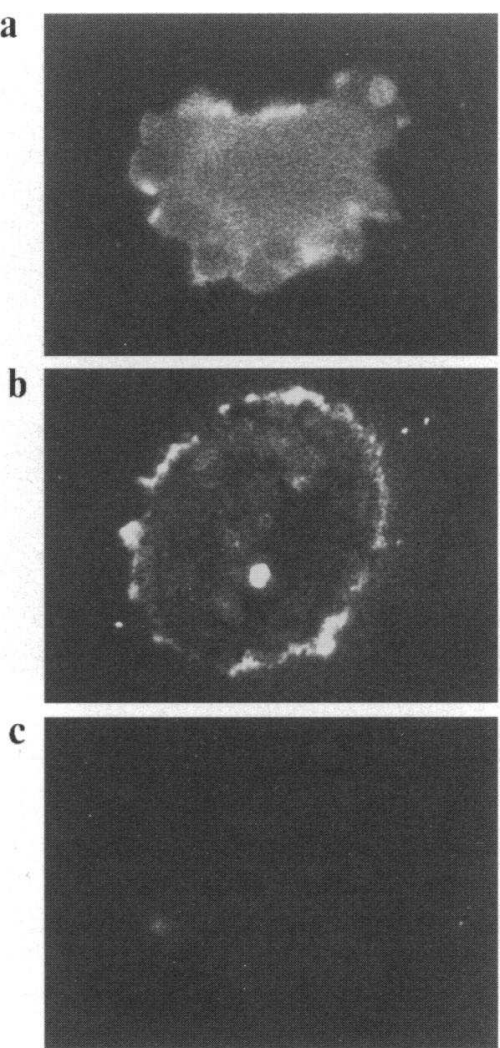

Figure 5. Fluorescent immunostaining of isolated osteoclasts that were incubated with the rabbit polyclonal antiserum $\mathrm{Ab}^{129}$ without ( $a$ and $b)$ or with (c) its competing peptide. The cells, when visualized under phase contrast optics at the end of each experiment, did not take up trypan blue. The other antisera, anti-type I RyR, $A b^{180}$ and $A b^{34}$ failed to stain intact live rat osteo50 um clasts.

osteoclast incubated with nonimmune rabbit serum. There was no evidence of gold labeling (up to one particle per examined field). In contrast, panel $b$ shows gold particles (shown by arrows) studded to the surface of an osteoclast that was incubated with antiserum $\mathrm{Ab}^{129}$. Between 4 and 15 such particles were seen in each examined field. Panel $c$ confirms the details of a spherical $30-\mathrm{nm}$ wide gold particle. These findings reinforce the our confocal micrographic data for a cell surface localization of the staining and thus provide strong evidence for the existence of a binding site for antiserum $\mathrm{Ab}^{129}$ on the surface of intact rat osteoclasts.

\section{Discussion}

We have demonstrated that a RyR-like molecule, expressed in the plasma membrane, is a functional component of the osteoclast $\mathrm{CaR}$. These studies were prompted by our previous observations which indicated an involvement of a ryanodine- and caffeine-sensitive molecule in extracellular $\mathrm{Ca}^{2+}$ sensing by the osteoclast $(27,28)$. We had found that both RyR modulators, ryanodine and caffeine, inhibited $\mathrm{CaR}$ activation by its wellcharacterized cation agonist, $\mathrm{Ni}^{2+} \cdot \mathrm{Ni}^{2+}$ interacts with the $\mathrm{CaR}$ and triggers the release of intracellularly stored $\mathrm{Ca}^{2+}(19)$, but blocks $\mathrm{Ca}^{2+}$ influx channels (25).

We have now extended this earlier work by examining the effects of the polycationic RyR inhibitor ruthenium red. In muscle, ruthenium red blocks $\mathrm{Ca}^{2+}$ release only when introduced into cells $(4,35)$. In contrast, we show here that the extracellular application of the dye to intact osteoclasts results in a markedly attenuated cytosolic $\mathrm{Ca}^{2+}$ response to applied $\mathrm{Ni}^{2+}$. These 

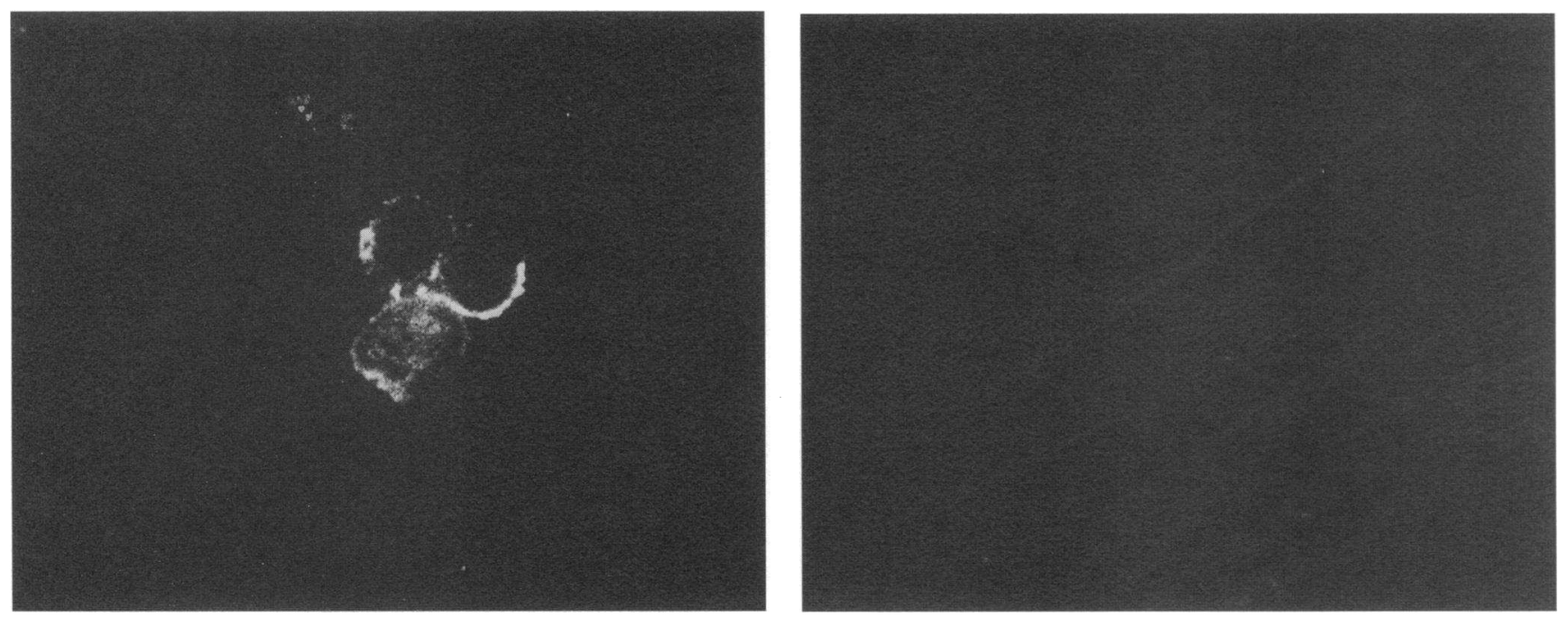

Figure 6. Confocal micrographs demonstrating fluorescent staining of isolated osteoclasts that were incubated with the rabbit polyclonal antiserum $\mathrm{Ab}^{129}$ without $(a)$ or with $(b)$ its competing peptide. Note the characteristic peripheral pattern of strong staining in $(a)$ and a very weak peripheral glow around the cells in $(b)$.

findings suggest that ruthenium red interacts with the $\mathrm{Ni}^{2+}$ sensitive $\mathrm{CaR}$ at the cell surface membrane. Interestingly, the calculated $K_{1}(43.6 \mathrm{nM})$ is close to that reported for RyRs of excitable cells (35).

To achieve greater specificity for detecting the putative RyR-like molecule, we used a panel of isoform- and regionspecific antisera. The only antiserum that yielded positive results in intact trypan blue-negative osteoclasts was $\mathrm{Ab}^{129}$ that had been raised to a short segment located within the channel-forming, COOH-terminal, domain of the type II RyR. Thus, when the cells were preincubated with $\mathrm{Ab},{ }^{129}$ their cytosolic $\mathrm{Ca}^{2+}$ responses to $\mathrm{Ni}^{2+}$ were potentiated dramatically by $\sim 10$-fold. To demonstrate that this potentiation specifically arose from the detection of its epitope by $A b^{129}$, we included the competing peptide before and during incubation with the antiserum. The observed potentiation was promptly abolished strongly indicating a positive interaction between the RyR-like molecule detected by the antibody and the $\mathrm{Ni}^{2+}$-binding site. We are nevertheless unclear as to the precise mechanism underlying the potentiation of the $\mathrm{Ni}^{2+}$-induced cytosolic $\mathrm{Ca}^{2+}$ response by the antiserum $A b^{129}$.

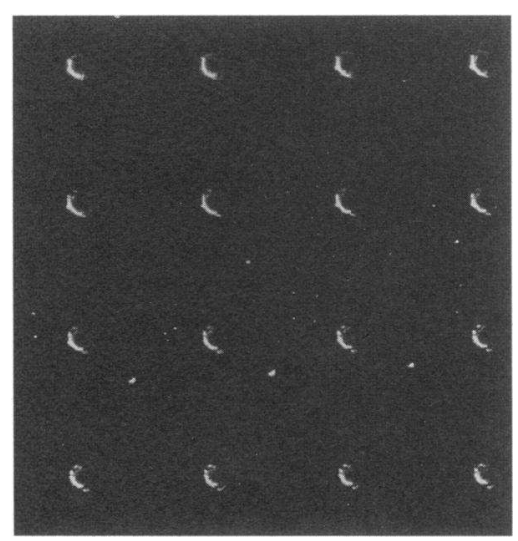

50 um

Figure 7. A series of confocal sections taken at 1 $\mu \mathrm{m}$ increments in the $\mathrm{z}$ axis of an osteoclast stained with antiserum $\mathrm{Ab}^{129}$. Note the consistent peripheral distribution of staining and a cytosolic sparing in the successive confocal planes.
That the antiserum $A b^{129}$ was specific for a unique epitope on the type II RyR was determined as follows. Firstly, a comparison of the $A b^{129}$ epitope sequence located within the predicted transmembrane segments 6 and 7 of the type II RyR (between amino acids 4643 and 4815) (29) with other sequences in the Leeds and Swissprot Databases revealed a lack of homology with any other known peptide sequence, thus establishing its uniqueness. This does not exclude the possibility that it is part of a yet unidentified protein. Secondly, the specificity of the antiserum $\mathrm{Ab}^{129}$ was confirmed by immunoblot analysis using microsomal membranes prepared from skeletal muscle, cardiac muscle, and brain. It was evident that $\mathrm{Ab}^{129}$ bound only the type II RyR isoform that is present in abundance in cardiac muscle and to a lesser extent in brain, and did not show any reactivity with the type $\mathrm{I}$ isoform present in skeletal muscle. Finally, both the binding of $A b^{129}$ to intact osteoclasts and its action in potentiating the effect of $\mathrm{Ni}^{2+}$ on cytosolic $\mathrm{Ca}^{2+}$ were abolished upon pretreatment of osteoclasts with the competing synthetic peptide. Taken together, the evidence strongly suggests that antiserum $\mathrm{Ab}^{129}$ detects a unique epitope that is present on the type II RyR, and on no other known protein.

We inferred from our results that the $A b^{129}$-reactive, RyRlike molecule was localized to the osteoclast plasma membrane.
Figure 8. Confocal micrograph showing fluorescent staining of an osteoclast which was first permeabilised with Triton X-100 and then incubated with antiserum $\mathrm{Ab}^{34}$. The distinctive intracellular staining, particularly showing outlining of the nuclei sharply contrasts with peripherally distributed surface staining pattern observed in Fig. 6. 

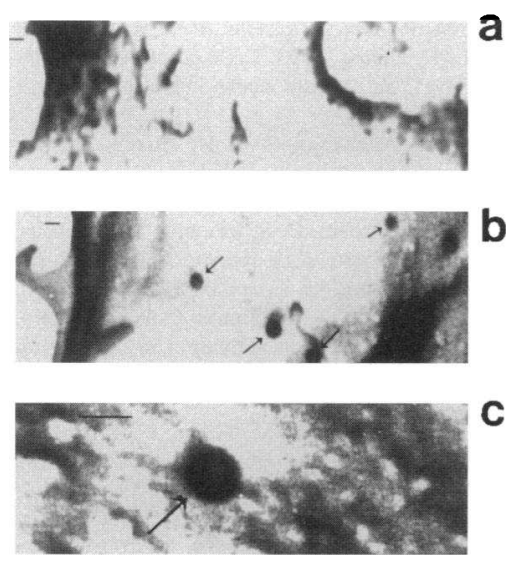

C mowing the details of a spherical gold particle. Scale bars represent $30 \mathrm{~nm}$ in all panels.

Surface localization was then confirmed independently by confocal microscopy and by scanning electron microscopy of immunostained osteoclasts. Confocal microscopy revealed that freshly isolated, intact, trypan blue-negative osteoclasts stained strongly with antiserum $\mathrm{Ab}^{129}$ in a characteristic plasma membrane pattern. Confocal images obtained in serial coronal planes in the cell's z-axis confirmed a plasma membrane localization of the staining. The staining was again markedly inhibited by preincubation of the cells with the competing peptide confirming the detection of the specific epitope by $\mathrm{Ab}^{129}$.

Finally, conclusive evidence for a plasma membrane localization of the epitope was obtained by scanning electronmicroscopic demonstration of specific immunogold labeling of the surface of intact osteoclasts.

Further controls for the observed surface interactions were provided by the negative results with the anti-type I RyR antiserum, as well as with antisera, $\mathrm{Ab}^{180}$ and $A b^{34}$. In particular, the latter antiserum was raised against a region in the central, presumed cytoplasmic, domain of the human type II RyR. Ab ${ }^{34}$ neither affected $\mathrm{CaR}$ activation by $\mathrm{Ni}^{2+}$ nor did it stain intact trypan blue-negative osteoclasts. It nevertheless strongly stained permeabilized cells in a distinctive cytoplasmic pattern indicating an intracellular localization of its epitope.

An interaction between $\mathrm{Ni}^{2+}$ and an RyR-like molecule was confirmed independently in autoradiographic studies that enabled a visualization of $\left[{ }^{3} \mathrm{H}\right]$ ryanodine binding to isolated osteoclasts. The specificity of such binding was confirmed by its displacement with the unlabeled ryanodine, which being freely permeant, completely displaced both intracellularly and extracellularly bound $\left[{ }^{3} \mathrm{H}\right]$ ryanodine. That this binding did indeed involve a RyR-like molecule was further confirmed by its displacement by ruthenium red. As the latter is cell impermeant, binding was not completely displaced. Nevertheless, even a partial attenuation of $\left[{ }^{3} \mathrm{H}\right]$ ryanodine binding by ruthenium red suggested a surface localization of the detected RyR-like molecule, thus reinforcing our data with $\mathrm{Ab}^{129}$. Finally, the cellimpermeant cation $\mathrm{Ni}^{2+}$ attenuated, but again did not abolish $\left[{ }^{3} \mathrm{H}\right]$ ryanodine binding, confirming an interaction between the RyR-like molecule and the CaR.

A surface-expressed RyR-like molecule could serve as a plasma membrane $\mathrm{Ca}^{2+}$ channel that is physically coupled to the osteoclast $\mathrm{CaR}$. This presumption could also apply to the parathyroid cell $\mathrm{CaR}$ which is a $\mathrm{G}$ protein-coupled membrane spanning receptor (36). Alternatively, the molecule could itself bind divalent cations. This would make biological sense if the $\mathrm{Ca}^{2+}$-binding site with a millimolar affinity, which is normally located intraluminally in the cardiac muscle (37), was to present extracellularly in the osteoclast. The site could then serve as a $\mathrm{Ca}^{2+}$ sensor in situ, given that the osteoclast is exposed to $\mathrm{Ca}^{2+}$ concentrations between 8 and $40 \mathrm{mM}$ during bone resorption (38).

The identity and orientation of the RyR-like molecule we detect remains unclear. Nevertheless, various possibilities exist. The molecule may be a structural homolog of the type II RyR which resides in microsomal membranes, but which may reach the plasma membrane through the fusion of intracellular vesicles akin to the insertion of the vacuolar $\mathrm{H}^{+}$-ATPase (39). The observation that the $\mathrm{Ab}^{34}$ epitope remains located intracellularly, and the putatively intraluminal $\mathrm{Ab}^{129}$ epitope is detected extracellularly, would indeed favor such a hypothesis. Alternatively, a variant of the known type II RyR may have achieved insertion directly into the plasma membrane. Finally, there is the remote possibility of there being a new, yet unidentified, molecule unrelated to the RyR family that nevertheless contains the $A b^{129}$-binding sequence. This seems very unlikely in view of the comprehensive nature of the evidence we provide for an RyR-like entity. Further investigations are thus urgently required to enable a structural characterization of this molecule.

\section{Acknowledgments}

The authors are grateful to Dr. T. Poulton and Mr. R. Moss (St. George's Hospital Medical School, London) for help with microscopy. Peter Starling, Esq. (The Physiological Laboratory, Cambridge, United Kingdom), Karl Straub (Little Rock, AR), and Lori Lemley (Little Rock, AR) kindly provided expert photographic assistance. Dr. Robert L. Jilka (Little Rock, AR) very kindly provided a critical assessment of our results. Finally, the authors wish to express their sincere gratitude to Professors Iain MacIntyre (William Harvey Research Institute, London) David Lipschitz, and Stavros Manolagas (Little Rock, AR) for their continued encouragement and support.

M. Zaidi is supported by the Arthritis and Rheumatism Council (Z0002) (United Kingdom), Medical Research Council (United Kingdom), and the Sandoz Foundation for Gerontological Research (Switzerland); B. R. Rifkin received a grant from the National Institutes of Health (DE 09576); A. R. Venkitaraman is supported by the Medical Research Council (United Kingdom); F. A. Lai acknowledges support of the British Heart Foundation and the Medical Research Council; and C. L.-H. Huang thanks the Royal Society for equipment support.

\section{References}

1. Meissner, G. 1994. The ryanodine receptor: structure and function. Annu. Rev. Physiol. 56:485-508.

2. Coronado, R., J. Morrissette, M. Sukhareva, and D. M. Vaughan. 1994. Structure and function of ryanodine receptors. Am. J. Physiol. 266:C1485-C1504.

3. Berridge, M. J. 1993. Inositol triphosphate and calcium signaling. Nature (Lond.). 361:315-325.

4. Huang, C. L.-H. 1993. Intramembrane Charge Movements in Striated Muscle. Clarendon Press, Oxford. 295 pp.

5. Lai, F. A., H. P. Erickson, E. Rousseau, Q. Y. Liu, and G. Meissner. 1988. Purification and reconstitution of the calcium release channel from skeletal muscle. Nature (Lond.). 331:315-319.

6. Fabiato, A. 1985. Time and calcium dependence of activation and inactivation of calcium-induced calcium release from the sarcoplasmic reticulum of a skinned canine cardiac Purkinje cell. J. Gen. Physiol. 85:247-289.

7. Brown, E. M. 1991. Extracellular calcium sensing, regulation of parathyroid 
cell function and role of calcium and other ions as extracellular first messengers. Physiol. Rev. 71:371-411.

8. Zaidi, M., A. S. M. T. Alam, C. L.-H. Huang, M. Pazianas, C. M. R. Bax, B. E. Bax, B. S. Moonga, P. J. R. Bevis, and V. S. Shankar. 1993. Extracellular $\mathrm{Ca}^{2+}$ sensing by the osteoclast. Cell Calcium. 14:271-277.

9. Malgaroli, A., J. Meldolesi, A. Zambonin-Zallone, and A. Teti. 1989. Control of cytosolic free calcium in rat and chicken osteoclasts. The role of extracellular calcium and calcitonin. J. Biol. Chem. 264:14342-14327.

10. Zaidi, M., H. K. Datta, A. Patchell, B. S. Moonga, and I. MacIntyre. 1989. "Calcium-activated" intracellular calcium elevation: a novel mechanism of osteoclast regulation. Biochem. Biophys. Res. Commun. 163:1461-1465.

11. Nemeth, E. F., and A. Scarpa. 1987. Are changes in intracellular free calcium necessary for regulation in parathyroid cells? Ann. NY Acad. Sci. 493:542-551.

12. Fried, R. M., and A. H. Tashjian. 1986. Unusual sensitivity of cytosolic free $\mathrm{Ca}^{2+}$ to changes in extracellular free $\mathrm{Ca}^{2+}$ in rat C-cells. J. Biol. Chem. 261:7669-7674.

13. Yamashita, $N$., and S. Hagiwara. 1990. Membrane depolarization and intracellular $\mathrm{Ca}^{2+}$ increase caused by high cisternal $\mathrm{Ca}^{2+}$ in a rat calcitonin secreting cell line. J. Physiol. 431:243-267.

14. Fray, J. C. S., C. S. Park, and N. D. Valentine. 1987. Calcium and control of renin secretion. Endocr. Rev. 8:53-93.

15. Pazianas, M., O. A. Adebarnjo, V. S. Shankar, S. V. James, K. W. Colston, J. D. Maxwell, and M. Zaidi. 1995. Extracellular cation sensing by the enterocyte production of a novel divalent cation sensor. Biochem. Biophys. Res. Commun. 210:448-453.

16. Hennings, H., D. Michael, C. Cheng, P. Steinert, K. Holbrook, and S. H. Yuspa. 1980. Calcium regulation of growth and differentiation of mouse epidermal cells in culture. Cell. 19:245-254.

17. Datta, H. K., I. MacIntyre, and M. Zaidi. 1990. The effect of extracellular calcium elevation on morphology and function of isolated rat osteoclasts. Biosci. Rep. 9:747-751.

18. Moonga, B. S., D. W. Moss, A. Patchell, and M. Zaidi. 1990. Intracellular regulation of enzyme release from rat osteoclasts and evidence for a functional role in bone resorption. J. Physiol. 429:29-45.

19. Shankar, V. S., C. M. R. Bax, B. E. Bax, A. S. M. T. Alam, B. Simon, M. Pazianas, B. S. Moonga, C. L.-H. Huang, and M. Zaidi. 1993. Activation of the $\mathrm{Ca}^{2+}$ receptor on the osteoclast by $\mathrm{Ni}^{2+}$ elicits cytosolic $\mathrm{Ca}^{2+}$ signals: evidence for receptor activation, intracellular $\mathrm{Ca}^{2+}$ redistribution and divalent cation modulation. J. Cell. Physiol. 155:120-129.

20. Bax, B. E., V. S. Shankar, C. M. R. Bax, A. S. M. T. Alam, S. J. Zara, M. Pazianas, C. L.-H. Huang, and M. Zaidi. 1993. Functional consequences of the interaction of $\mathrm{Ni}^{2+}$ with the osteoclast $\mathrm{Ca}^{2+}$ receptor. Exp. Physiol. 78:517529.

21. Pazianas, M., M. Zaidi, C. L.-H. Huang, B. S. Moonga, and V. S. Shankar. 1993. Voltage-sensitivity of the osteoclast calcium receptor. Biochem. Biophys. Res. Commun. 192:1100-1105.

22. Shankar, V. S., C. L.-H. Huang., O. Adebanjo, B. J. Simon, A. S. M. T Alam, B. S. Moonga, M. Pazianas, R. H. Scott, and M. Zaidi. 1995. The effect of membrane potential on surface $\mathrm{Ca}^{2+}$ receptor activation in rat osteoclasts. $J$. Cell. Physiol. 162:1-8.

23. Caputo, C. 1981. Nickel substitution for calcium and the time course of potassium contractures of single muscle fibers. J. Muscle Res. Cell Motil. 2:167182.

24. Almers, W., and P. T. Palade. 1981. Slow calcium and potassium currents across frog muscle membrane: measurements with a vaseline gap technique. $J$. Physiol. 312:159-176.

25. Zaidi, M., V. S. Shankar, C. M. R. Bax, B. E. Bax, P. J. R. Bevis, M Pazianas, A. S. M. T. Alam, and C. L.-H. Huang. 1993. Linkage of extracellular and intracellular control of cytosolic $\mathrm{Ca}^{2+}$ in rat osteoclasts in the presence of thapsigargin. J. Bone Miner. Res. 8:961-967.

26. Zaidi, M., V. S. Shankar, O. A. Adebanjo, C. L.-H. Huang, and M. Pazianas. 1994. Cell surface protein cleavage by pronase abolished calcium receptor activation by divalent cations. J. Bone Miner. Res. 9 (Suppl. 1):C105.

27. Zaidi, M., V. S. Shankar, A. S. M. T. Alam, B. S. Moonga, M. Pazianas, and C. L.-H. Huang. 1992. Evidence that a ryanodine receptor triggers signal transduction in the osteoclast. Biochem. Biophys. Res. Commun. 188:1332-1336.

28. Shankar, V. S., M. Pazianas, C. L.-H. Huang, B. Simon, O. A. Adebanjo, and M. Zaidi. 1995. Caffeine modulates $\mathrm{Ca}^{2+}$ receptor activation in isolated rat osteoclasts and induces intracellular $\mathrm{Ca}^{2+}$ release. Am. J. Physiol. 268:F447F454.

29. Zorzato, F., J. Fujii, K. Otsu, M. Phillips, N. M. Green, F. A. Lai, G. Meissner, and D. H. MacLennan. 1990. Molecular cloning of cDNA encoding human and rabbit forms of the calcium release channel (ryanodine receptor) of skeletal muscle sarcoplasmic reticulum. J. Biol. Chem. 265:2244-2256.

30. Zaidi, M., H. K. Datta, B. S. Moonga, and I. MacIntyre. 1990. Evidence that the action of calcitonin on rat osteoclasts is mediated by two $G$ proteins acting via separate post-receptor pathways. J. Endocrinol. 126:473-481.

31. Zaidi, M., A. S. M. T. Alam, C. Bax, V. S. Shankar, P. J. R. Bevis, C. L.-H. Huang, M. Pazianas, and B. S. Moonga. 1994. Cytosolic free calcium measurements in single cells using calcium-sensitive fluorochromes. In Methods in Molecular Biology. Volume 27, Biomembrane Protocols II. J. M. Graham and J. A. Higgins, editors. Humana Press Inc., Totowa, New Jersey. 279-293.

32. Anderson, K., F. A. Lai, Q. Y. Liu, H. P. Erickson, and G. Meissner 1989. Structural and functional characterisation of the purified cardiac ryanodine receptor-calcium release channel complex. J. Biol. Chem. 264:1329-1335.

33. Lai, F. A., M. Dent, C. Wickenden, G. Kumari, M. Misra, H. B. Lee, M. Sar, and G. Meissner. 1992. Expression of a cardiac calcium release channel isoform in mammalian brain. Biochem. J. 288:553-564.

34. Csernoch, L., G. Pizarro, I. Uribe, M. Rodriguez, and E. Rios. 1992. Interfering with calcium release suppresses $I \gamma$ the hump component of intramembranous charge movement in skeletal muscle. J. Gen. Physiol. 97:845-884.

35. Baylor, S. M., S. Hollingworth, and M. W. Marshall. 1989. Effects of intracellular ruthenium red on excitation-contraction coupling in intact frog skeletal muscle fibres. J. Physiol. 408:617-635.

36. Brown, E. M., G. Gamba, I. D. Riccardi, M. Lombardi, R. Butters, O. Kifor, A. Sun, M. A. Hediger, J. Lytton, and S. C. Hebert. 1993. Cloning and characterization of an extracellular calcium sensing receptor from bovine parathyroid. Nature (Lond.). 366:575-579.

37. Ashley, R. H., and A. J. Williams. 1990. Divalent cation activation and inhibition of single calcium release channels from sheep cardiac sarcoplasmic reticulum. J. Gen. Physiol. 95:981-1005.

38. Silver, I. A., R. J. Murrills, and D. J. Etherington. 1988. Microelectrode studies on acid microenvironment beneath adherent macrophages and osteoclasts. Exp. Cell Res. 175:266-276.

39. Baron, R. 1989. Molecular mechanisms of bone resorption by the osteoclast. Anat. Rec. 224:317-324. 